ISSN: 2644-1209

\title{
Demography and Population Aging
}

\author{
Patrice F Dassonville* \\ Author of the Invention of Time and Space: Origins, Definitions, Nature, Properties, France
}

Received: 阱 October 1, 2018; Published: 畊 October 05, 2018

*Corresponding author: Patrice F Dassonville, Author of The Invention of Time and Space : Origins, Definitions, Nature, Properties, Rue Latour-Maubourg, 06400 Cannes, France

Abstract

Demographes and economistes warn about a phenomenon which is currently observed in developed nations: The population aging. The analysis of the causes of this disappointing verdict lets think that time could be a misleading demographic parameter.

\section{Introduction}

Time is not a phenomenon; instead it's a concept. Therefore time is not the cause of aging of an individual nor is it the cause of aging of a population [1]. We are wondering why the average age is higher in developed nations and why it is lower in underdeveloped nations. What are the causes of this Strange contrast. The increase of the average age is an expected syndrome of the development of a nation. Therefore, time appears as a deceptive demographic indicator.

\section{Chronological Age and Biological Age}

Chronological age is commonly called age; it's a concept of time which is expressed with some numbers (years, months and days since the beginning); the information are very poor. Medicine has introduced the concept of biological age which takes into account physical and mental health of the individual , the quality of life, the cultural level. Unfortunately the collection of these data is difficult; but the information is very rich, and it is paramount in economics and in sociology to smartly evaluate a situation and take appropriate political decisions. For example, quality of life is now taken into account by some OECD statistics.

\section{Etiology of Aging}

The word etiology comes from the Greek, aitia, which means cause, aitiologia means study of causes. Aging affects all living and hardware systems; it results from three main factors: endogenous factors, exogenous factors, and frequent potentiation of both. Jonathan Hutchinson and Hastings Gilford have identified a genetic anomaly of which results an accelerated biological aging at the infant age, with no action on chronological age.
Let's mention two examples in construction engineering.The Tower of Pisa ( $12^{\text {th }}$ century), is an example of change not from time, but from insufficient foundations (Figure 1). It's a famous example of the syndrome of Hutchinson-Gilford. The collapse of the bridge of Genova in August 2018 is another illustration of the syndrome of Hutchinson-Gilford, not from time but from low quality of materials, errors in structures calculations or improper maintenance. It's interesting to compare with Roman and Egyptian architecture.

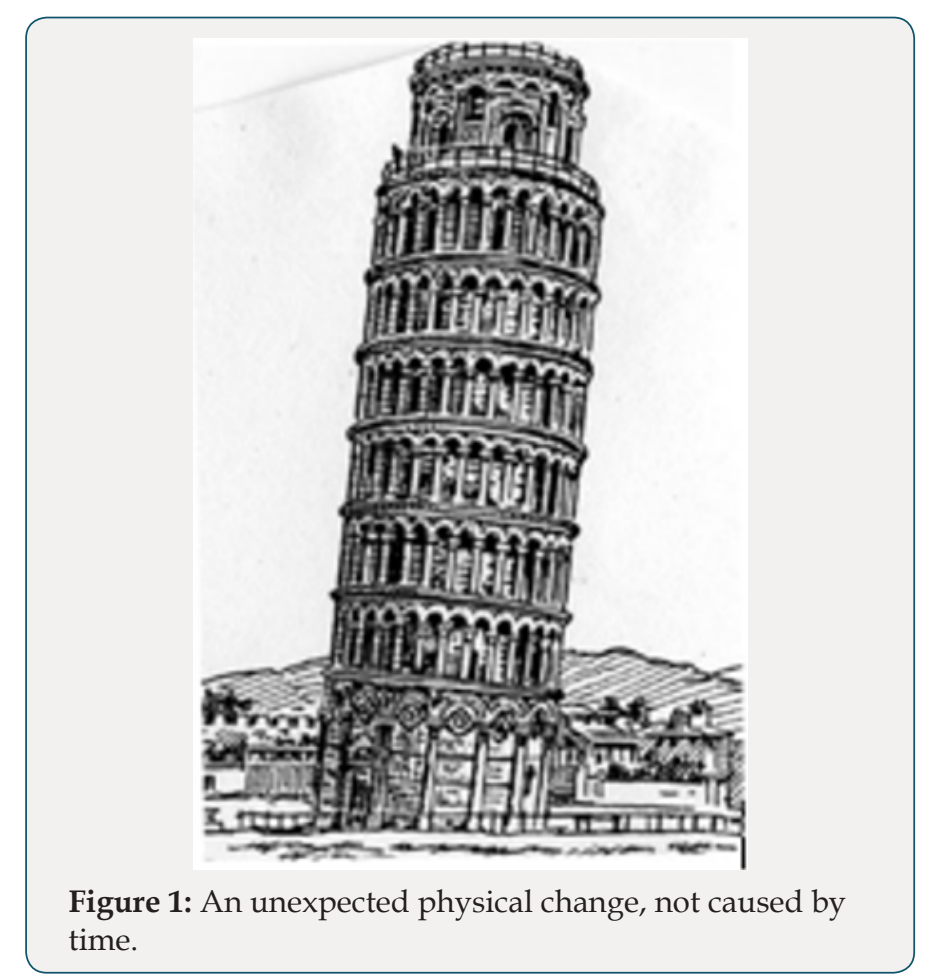




\section{Causes of Aging of Bacteria}

The innocuity of time on aging of bacteria is demonstrated in combining observations with a mathematical model [1]. At each generation, the population doubles.

$$
1 \text {--> } 2 \text {--> } 4 \text {--> } 8 \text {--> } 16 \text {--> } 32 \text { - - - } 2 \exp (n)
$$

If we start with « $\mathrm{N}_{0}$ » bacteria, at the $" \mathrm{n}^{\text {th }}$ » generation the population of bacteria will be

$$
\mathrm{N}=\mathrm{N}_{0} 2 \exp (\mathrm{n})
$$

In an homogenous medium, the generations reproduce at approximmately the same rate « $\mu$ (Greek letter mu), and the number $« \mathrm{n}$ » of generation is

$$
\mathrm{n}=\mu \mathrm{t}
$$

The number of bacteria finally reads

$$
\mathrm{N}=\mathrm{N}_{0} 2 \exp (\mu \mathrm{t})
$$

Time « $\mathrm{t}$ » is not involved in the experiment; it is what the clock of the laboratory indicates. The proliferation rate $" \mu$ » has various causes such as temperature, humidity, gravity, presence of sugar, specific genotype, and possible potentiation of these factors, one making the other more effective in some way. « $\mu$ » contains all these componants. Sugar increases the speed of duplication of bacteria; therefore it reduces the lifetime of a population of bacteria, because the rate of scissiparity is approximately limited to 60. Prof. Valter Longo has observed that bacteria could triple their lifetime when they are deprived of sugar [2].

\section{Causes of Aging of an Individual}

For Horace, during their course, the years strip us all our advantages [3]. Horace thought that time was the main cause of aging. In the early twentieth centutry, someone 60 years old was an old person; at same age, nowadays he is in a much better health status. In January 2017, the French Robert Martin 105 years old, broke his bike record by traveling $22 \mathrm{~km}$ in one hour. The aging of an individual does not result from time; instead, it results from numerous causes including junk food, lack of hygiene, lack of medicalization, exposure to ionizing factors which produce free radicals, genetic inheritance. According to Prof. Longo there are three aging genes. [2].

\section{Demography and Age}

During classical period, lifetime was about 25 years, mainly in reason of infant mortality [4]. Demographers take into account the chronological age rather than the biological age; the chronological age distribution of a population is easy to measure, but unfortunately, it does not contain much information. In underdeveloped countries, the average age is low because infant mortality between 0 and 6 years is about $50 \%$. Adults die young, in reason of the deficit or the absence of the factors of progress. Marveling about the youthfulness of a population and about the demographic dynamics in coutries with low average age, is a error of analysis, which is driven by ignorance of the nature of time; this youthfulness and this pretended demographic dynamics are paid at price of a high birth rate and of an important premature deaths rate, which lower statistical averages.

The expressions population old age and population aging, which describe demography of developped countries, are misleading. The median chronological age (poorly informative) and the biological age (physical and mental health) are widely diverging.

\section{Conclusion}

The combination of a statistical modeling based on temporal parameters, distorts the evaluation of reality by conveying a falsified information; age, that is to say time, is a faulty indicator in this specific case.The increase of average age of a population, is a normal result of health progress, caused by feeding, by hygiene, by medicalization, by education and by mastering of demography. It leads to the theorem: a low average age is a syndrome of underdevelopment.

\section{References}

1. Dassonville P (2017) The Invention of Time and Space. Springer.

2. Valter Longo, USA.

3. Horace, Epistles.

4. Barguet A (1964) Herodotus L’Enquête. Gallimard, France.
(C) (P) This work is licensed under Creative

To Submit Your Article Click Here: Submit Article

DOI: $10.32474 /$ TOOAJ.2018.01.000125

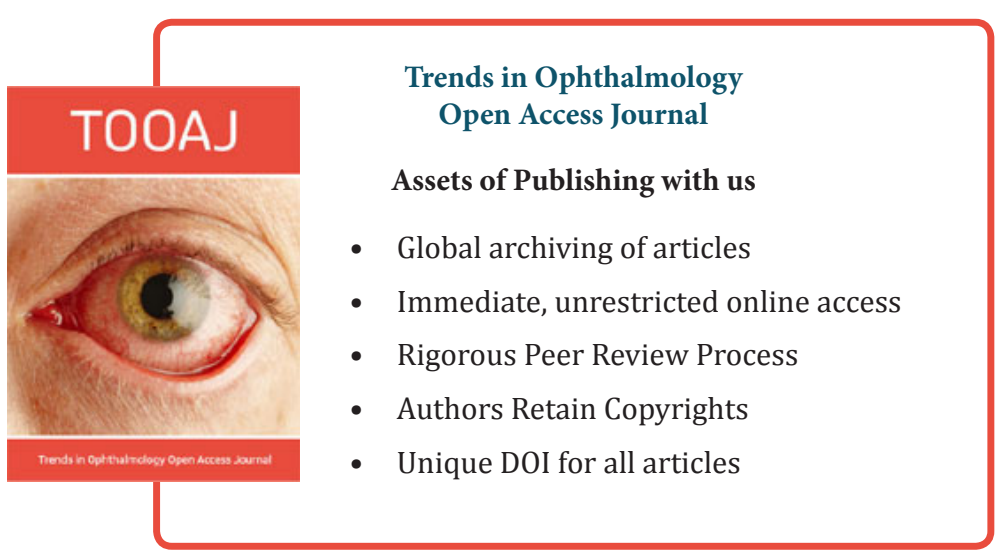

